\title{
Inverse relationship between insulin receptor expression and progression in renal cell carcinoma
}

\author{
MAKOTO TAKAHASHI $^{1^{*}}$, TAKAMITSU INOUE ${ }^{1,2^{*}}$, MINGGUO HUANG $^{1,2}$, KAZUYUKI NUMAKURA $^{1}$, \\ HIROSHI TSURUTA ${ }^{1}$, MITSURU SAITO ${ }^{1}$, ATSUSHI MAENO ${ }^{1}$, EIJIRO NAKAMURA ${ }^{3}$, \\ SHINTARO NARITA $^{1,2}$, NORIHIKO TSUCHIYA ${ }^{4}$ and TOMONORI HABUCHI ${ }^{1,2}$ \\ ${ }^{1}$ Department of Urology, Akita University Graduate School of Medicine, Akita; \\ ${ }^{2}$ AMED-CREST, Japan Science and Technology Agency, Tokyo; ${ }^{3}$ Laboratory for Malignancy Control Research, \\ Medical Innovation Center, Kyoto University Graduate School of Medicine, Kyoto; \\ ${ }^{4}$ Department of Urology, Yamagata University Faculty of Medicine, Yamagata, Japan
}

Received August 9, 2016; Accepted September 23, 2016

DOI: $10.3892 /$ or.2017.5552

\begin{abstract}
We investigated the relationship among serum insulin level, insulin receptor (IR) expression in renal cell carcinoma (RCC), and outcomes in patients with RCC who underwent nephrectomy. We also explored the role of insulin signaling in RCC progression in a murine RCC allograft RENCA model using metformin to treat hyperinsulinemia induced by a high-carbohydrate diet. Clinically, the IR expression level in RCC tissue was significantly lower in patients with tumor stage pT2-4 and/or distant metastases. The IR expression level in RCC tissue was significantly lower in patients with preoperative serum C-peptide levels greater than or equal to the median than in patients with levels less than the median. High IR expression level was significantly associated with better disease-free and overall survival after nephrectomy. The IR expression level was significantly higher in murine subcutaneous flank tumors of the low-carbohydrate diet group and high-carbohydrate diet plus metformin group than of the high-carbohydrate diet group. In vivo progression of murine tumors was not significantly enhanced by hyperinsulinemia induced by a high-carbohydrate diet and was significantly inhibited by metformin in both the low- and high-carbohydrate diet groups. IR expression in RCC tissue was inversely
\end{abstract}

Correspondence to: Dr Takamitsu Inoue, Department of Urology, Akita University Graduate School of Medicine, 1-1-1 Hondo, Akita 010-8543, Japan

E-mail: takamitu@doc.med.akita-u.ac.jp

*Contributed equally

Abbreviations: DM, diabetes mellitus; RCC, renal cell carcinoma; IR, insulin receptor; IGF1R, insulin-like growth factor 1 receptor; BMI, body mass index

Key words: renal cell carcinoma, insulin receptor, hyperinsulinemia, immunohistochemistry, murine allograft, high-carbohydrate diet, metformin associated with cancer progression in the clinical and murine experimental model studies. The clinical and murine allograft model study results suggested that hyperinsulinemia does not promote RCC progression. Decreased IR expression in high-stage RCC tumors with poor prognosis may be the result of downregulation induced by the host's hyperinsulinemia.

\section{Introduction}

Epidemiological studies have suggested an association among obesity, type 2 diabetes mellitus (DM) and cancer (1). Insulin resistance induces hyperinsulinemia in patients with obese or early-stage type 2 DM (2). Insulin is not only a key regulator in carbohydrate metabolism, but also a strong mitogenic molecule that activates the PI3K/Akt/mTOR pathway (3). Increased insulin signaling induced by hyperinsulinemia may play a significant role in carcinogenesis and cancer progression in patients with obesity or DM (3).

Regarding the recent increased incidence of renal cell carcinoma (RCC) (4), it has been reported that the association between obesity and the incidence of RCC was stronger than that of prostate or breast cancers (5-8). Moreover, it has also been reported that type $2 \mathrm{DM}$ is associated with the incidence of RCC (9-11), an association that has also been observed for prostate and breast cancer $(9,10,12,13)$.

In contrast, regarding progression of RCC, numerous epidemiological studies have provided strong evidence that the prognosis of obese patients with RCC is better than that of non-obese patients, a finding that has been called the 'obese paradox' in RCC (14-21). However, the prognosis of obese patients has been reportedly poor in prostate cancer (22-24), and not different from that of non-obese patients in breast cancer $(25,26)$. There appears to be an inverse relationship between cancer incidence and progression in patients with RCC. Recent studies have shown a positive relationship between pre-existing type $2 \mathrm{DM}$ and poor RCC prognosis (27), or no significant relationship (28). It is plausible that the insulin-signaling pathway activated by hyperinsulinemia may play a significant role in the progression and 'obese paradox' of RCC. 
Previous studies have shown that insulin receptor (IR) expression is higher in RCC tumors than that in normal proximal convoluted tubules (29) and was inversely associated with the Fuhrman's grade (30). In breast cancer, IR expression has been reported to be positively $(31)$ or negatively $(32,33)$ associated with cancer progression. Phosphorylation of insulin-like growth factor 1 receptor (IGF1R/IR), detected by immunohistochemistry (31), and a high fasting serum insulin level $(34,35)$ have been associated with poor prognosis in breast cancer. In prostate cancer, IR expression and serum C-peptide levels have been associated with histological grade and cancer-specific survival, respectively $(36,37)$. In a murine xenograft model of prostate cancer, hyperinsulinemia induced by a high-carbohydrate diet was found to be associated with cancer progression and activation of insulin-signaling pathways (38). However, there have been no reports of animal studies investigating the role of hyperinsulinemia, IR expression and downstream signaling pathways in the progression of RCC.

In the present study, we investigated the role of hyperinsulinemia, IR expression and insulin signaling in RCC progression. Initially, we evaluated the relationship among IR expression, the serum C-peptide level, and cancer prognosis in patients with RCC who underwent nephrectomy. We then explored the role of insulin signaling in a murine RCC allograft model in obese, hyperglycemic and hyperinsulinemic mice induced by a high-carbohydrate diet. Furthermore, we used biguanide metformin, which is a common anti-type 2 diabetes agent, to investigate whether the indirect effect of metformin on the decrease of serum insulin levels (3) inhibits murine RCC progression.

\section{Materials and methods}

Patients and immunohistochemistry. A total of 99 patients who underwent nephrectomy for RCC from February 2007 to June 2011 were included in the immunohistochemical analysis. Fifteen and 84 patients underwent partial and radical nephrectomy, respectively. The characteristics of the patients are presented in Table I. All patients provided written informed consent and the study protocols regarding immunohistochemical analyses were approved by the Akita University Medical Center Institutional Review Board. The histology of the 99 RCC tumors was clear cell in 83, papillary type 2 in 8 , chromophobe in 4 , and spindle cell in 4 cases. The tumor specimens, which were $20 \%$ formalin-fixed and paraffin-embedded, were sliced into 5- $\mu \mathrm{m}$ thick sections and immunohistochemically analyzed using anti-IR- $\beta$ subunit (\#07-724; Millipore, St. Charles, MO, USA) and anti-IGF1R $\beta$ subunit antibodies (\#3024; Cell Signaling Technology, Danvers, MA, USA). Each of the stained sections was scored according to the Allred scoring method (39), which adds the intensity of staining (absent, 0; weak, 1; moderate, 2; and strong, 3) to the percentage of carcinoma cells stained (none, $0 ;<1 \%, 1 ; 1-10 \%, 2 ; 11-33 \%, 3$; $34-66 \%, 4$; and $67-100 \%, 5)$. The intensity of staining was defined focusing on the intensity of the membranous and/or cytoplasmic staining in the evaluation of the IR and IGF1R expression. The total expression score was calculated as the sum of the 2 parameters. Serum specimens were collected from the patients before surgery and the serum C-peptide and
Table I. Demographic data of the 99 patients who underwent nephrectomy.

\begin{tabular}{|c|c|}
\hline Demographics & $\mathrm{n}=99$ \\
\hline \multicolumn{2}{|l|}{ Gender } \\
\hline Male & 70 \\
\hline Female & 29 \\
\hline Median age, in years (range) & $63.5(22-93)$ \\
\hline BMI (median (range) & $23.0(16-37)$ \\
\hline \multicolumn{2}{|l|}{ Type 2 diabetes mellitus } \\
\hline Yes & 19 \\
\hline Treated with insulin & 6 \\
\hline No & 80 \\
\hline \multicolumn{2}{|l|}{ Nephrectomy } \\
\hline Partial & 15 \\
\hline Radical & 84 \\
\hline \multicolumn{2}{|l|}{ TNM stage } \\
\hline pT1 & 65 \\
\hline pT2 & 12 \\
\hline pT3 & 21 \\
\hline pT4 & 1 \\
\hline No & 88 \\
\hline N1 & 4 \\
\hline $\mathrm{N} 2$ & 7 \\
\hline M0 & 82 \\
\hline M1 & 17 \\
\hline \multicolumn{2}{|l|}{ Pathology } \\
\hline Clear cell renal cell carcinoma & 84 \\
\hline Papillary renal cell carcinoma type 2 & 7 \\
\hline Spindle cell carcinoma & 4 \\
\hline Chromophobe renal cell carcinoma & 4 \\
\hline \multicolumn{2}{|l|}{ Fuhrman grade } \\
\hline G1 & 25 \\
\hline $\mathrm{G} 2$ & 40 \\
\hline G3 & 34 \\
\hline
\end{tabular}

Immunohistochemistry score ${ }^{\mathrm{a}}$

IR expression

$0-2 \quad 10$

$3-5 \quad 65$

$6 \quad 15$

$\begin{array}{ll}7-8 & 9\end{array}$

IGF1R expression

$0-2 \quad 12$

$3-5 \quad 59$

$6 \quad 18$

$\begin{array}{ll}7-8 & 10\end{array}$

${ }^{a}$ Immunohistochemistry was scored according to the Allred scoring method. BMI, body mass index; TNM, tumor-node-metastasis; IR, insulin receptor; IGF1R, insulin-like growth factor 1 receptor.

IGF1 levels were assessed using a chemiluminescent enzyme immunoassay for C-peptide or radioimmunoassay for IGF1. 
Cell culture. Human RCC cell lines (786-O, Caki-1, Caki-2 and ACHN) and a murine cell line, RENCA, were purchased from the American Type Culture Collection (ATCC; Manassas, VA, USA) and maintained in Roswell Park Memorial Institute (RPMI)-1640 medium supplemented with $10 \%$ fetal bovine serum (FBS) at $37^{\circ} \mathrm{C}$ in a $5 \% \mathrm{CO}_{2}$-humidified incubator. $786-\mathrm{O}$, Caki-1, Caki-2, ACHN, RENCA and LNCaP cells which were purchased from ATCC were authenticated by STRS analysis. RENCA was used in cell proliferation assays, western blotting, and in vivo murine experiments within 6 passages after being purchased from ATCC.

Cell proliferation assay. RENCA cells were plated at $5 \times 10^{3}$ cells/well onto 96 -well plates in culture medium containing $10 \%$ FBS. After a $24-\mathrm{h}$ incubation in serum-free medium, the medium was completely replaced with a test medium containing various doses of insulin or metformin for $72 \mathrm{~h}$. Then, a $1 \mathrm{mg} / \mathrm{ml}$ solution of 3-(4,5-dimethylthiazol-2-yl)-2,5-diphenyltetrazolium bromide (MTT) was added to each well, and all plates were incubated for $3 \mathrm{~h}$. After the MTT solution was removed, $0.05 \mathrm{~N}$ isopropanol- $\mathrm{HCl}$ solution was added, and the optical density was assessed between 570 and $650 \mathrm{~nm}$ using a spectrometer.

Animals, diets and metformin. All procedures used in the animal experiments were approved by the Institutional Review Board of the Akita University School of Medicine. Seventy-two female C57BL/6 NCrl mice aged 5-6 weeks (Charles River Laboratories, Inc., Yokohama, Japan) were randomized into 2 groups for the initial experiment and 4 groups for the second experiment: low- and high-carbohydrate diet groups for the initial experiment, and low- and high-carbohydrate diet, low-carbohydrate diet plus metformin, and high-carbohydrate diet plus metformin groups for the second experiment. Each group contained 12 mice and only 2 mice were placed in each cage to prevent fighting.

The food was administered ad libitum. The high- and low-carbohydrate diets were provided by Ren's Feed and Supplies Ltd. (\#5381 and \#5382) (38). The caloric amounts in each diet were adjusted to be equal. The energy contributions of the carbohydrate, fat, and protein contents in the high- and low-carbohydrate diets were 47.5 and $11.4 \%$ for carbohydrates, 44.9 and $44.7 \%$ for fats and 15.1 and $45.1 \%$ for proteins.

Metformin (\#130-15485; Wako, Osaka, Japan) was administered at a dose of $50 \mathrm{mg} / \mathrm{kg}$ body weight/day via the drinking water from the beginning of the experiment. The concentration of metformin in the water was adjusted to $0.124 \mathrm{mg} / \mathrm{ml}$, so that a $30 \mathrm{~g}$ mouse would consume $1.5 \mathrm{mg}$ of metformin in $7 \mathrm{ml}$ of water/day. The water and metformin were changed weekly, and the dose was adjusted for weight gain every 2 weeks (40).

Glucose tolerance test. Glucose tolerance tests were performed at 8-14 weeks after the randomization to start the experimental diets and metformin. Blood glucose levels were assessed before i.p. injection of $1.5 \mathrm{~g} / \mathrm{kg}$ glucose at 30,60 and $90 \mathrm{~min}$ after the glucose injection using a OneTouch Ultra glucometer (Lifescan Inc., Scotland, UK), and blood was collected from a severed saphenous vein.
Murine RCC allograft model. A total of $2 \times 10^{5}$ RENCA cells were mixed in serum-free RPMI-1640 medium and subcutaneously injected into the right flanks of the C57BL/6 NCrl mice using a 26-gauge 1-ml syringe at 9-19 weeks after the randomization to start the experimental diets and metformin. Once the tumor became palpable, the tumor volume was calculated twice a week according to the following formula: [Tumor volume $=(\text { short diameter })^{2} \mathrm{x}$ long diameter $\mathrm{x} 0.52$ ].

All of the mice were starved overnight and euthanized under anesthesia using isoflurane. Blood samples were collected from the left ventricle using 24-gauge needles, and the flank tumors were excised under anesthesia. The excised tumors were stored into cryotubes and frozen immediately in liquid nitrogen and stored in a $-80^{\circ} \mathrm{C}$ deep freezer until sodium dodecyl sulfate-polyacrylamide gel electrophoresis (SDS-PAGE) and immunoblotting were performed. The collected blood was centrifuged at 3,000 rpm for $10 \mathrm{~min}$, and the serum was stored at $-80^{\circ} \mathrm{C}$ until the measurement. The serum insulin level was asssessed using a rat/mouse insulin enzyme-linked immunosorbent assay (ELISA) kit (\#EZRMI-13K; Millipore).

Immunoblotting. Tumor tissues or cells on the plates were homogenized in lysis buffer consisting of $50 \mathrm{mM}$ HEPES, $1 \%$ Triton $\mathrm{X}-100,150 \mathrm{mM} \mathrm{NaCl}, 0.02 \%$ sodium azide, $60 \mathrm{mM} \beta$-glycerophosphate, $1 \mathrm{mM}$ DTT, Complete Protease Inhibitor Cocktail (\#1169749800) and PhosSTOP Phosphatase Inhibitor Cocktail Tablets (\#04906845001) (both from Roche Diagnostics GmbH, Mannheim Germany) using a homogenizer (\#S8N-5G; IKA ${ }^{\circledR}$-Werke GmbH \& Co., Staufen, Germany). The lysates were centrifuged at $13,000 \mathrm{rpm}$ for $50 \mathrm{~min}$ at $4^{\circ} \mathrm{C}$, and the supernatant was collected and stored at $-80^{\circ} \mathrm{C}$. The protein concentration of the supernatant was measured using a protein assay reagent (BCA protein assay kit; Thermo Fisher Scientific, Waltham, MA, USA).

A total of $30 \mu \mathrm{g}$ of protein lysate/sample was subjected to $10 \%$ SDS-PAGE after being denatured by boiling at $100^{\circ} \mathrm{C}$ for 10 min with SDS sample buffer (\#AE-1430; ATTO, Tokyo, Japan). After blocking using 5\% skim milk, the membranes were probed using an iBlot ${ }^{\circledR}$ Dry Blotting System (Thermo Fisher Scientific) and antibodies specific for various molecules and $\beta$-actin (\#4967; Cell Signaling Technology). Membranes were treated with the appropriate peroxidase-conjugated secondary antibodies (\#7074s; Cell Signaling Technology) and visualized using the enhanced chemiluminescence reagent ECLTM system (\#RPN2232; Amersham, Piscataway, NJ, USA). The signal was captured using a chemiluminescence imaging system (\#AE-9300; ATTO).

Antibodies. Phospho-IGF1R (Tyr1135/1136)/IR (Tyr1150/1151; \#3024), total IR- $\beta$ subunit (\#07-724; Millipore), total IGF1R- $\beta$ subunit (\#3027), phospho-Akt (Ser473; \#9271), total Akt (\#9272), phospho-p44/42 mitogen-activated protein kinase (MAPK) (Thr202/Tyr204; \#9101), total p44/42MAPK (\#9102), phospho-p70 S6K (Thr389; \#9205), total p70 S6K (\#9202) and $\beta$-actin (\#4967) were used for immunoblotting. All the antibodies were purchased from Cell Signaling Technology except for the total IR- $\beta$ subunit antibody (\#07-724; Millipore).

Statistical analysis. The Chi-squared test was used to examine the relationship between the status of IR expression 

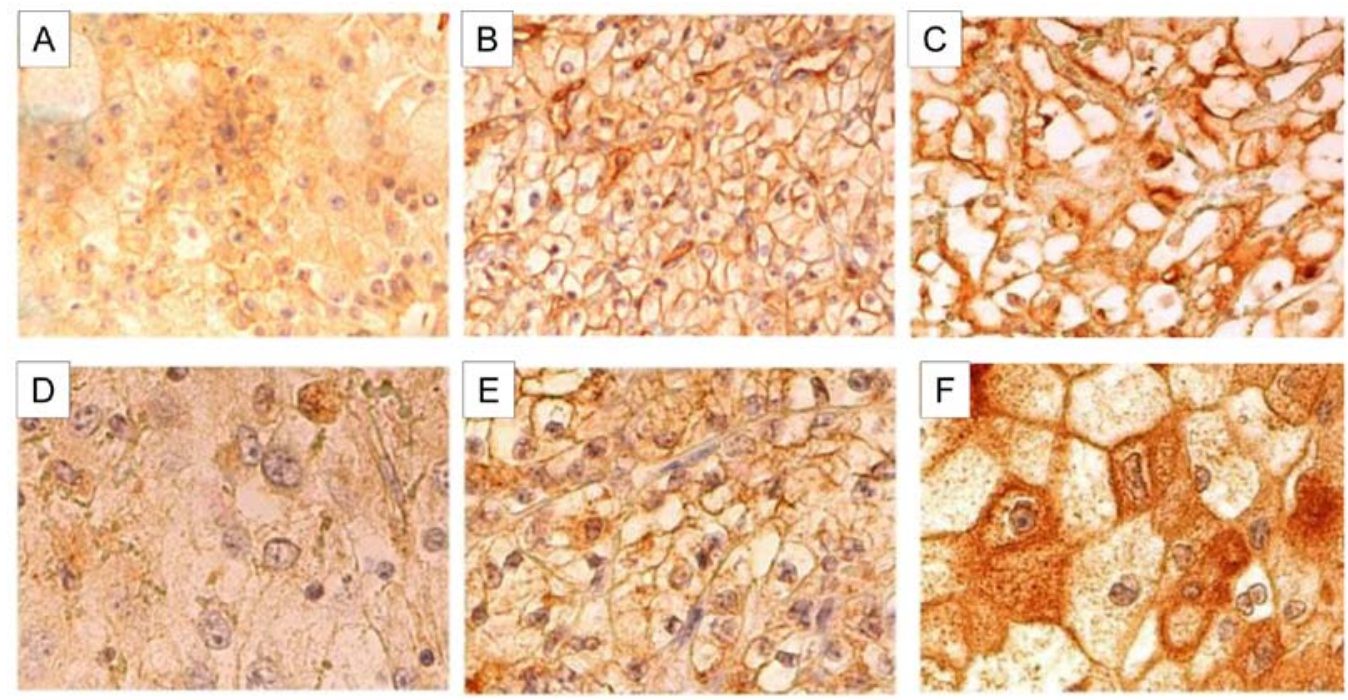

Figure 1. Representative panel of immunohistochemical staining of primary kidney tumors. Examples of strength in immunostaining with total IR- $\beta$ subunit and total IGF1R- $\beta$ subunit antibodies are shown for (A) IR grade 1, (B) IR grade 2, (C) IR grade 3, (D) IGF1R grade 1, (E) IGF1R grade 2, and (F) IGF1R grade 3. IR, insulin receptor; IGF1R, insulin-like growth factor 1 receptor.

and clinical parameters. To analyze survival after radical nephrectomy, the log-rank test and Cox proportional hazard model were used. A one-way repeated measures analysis of variance (ANOVA)-covariance model and Student's t-test were used to determine between-group differences and within-group changes overtime, respectively. All statistical analyses were performed using SPSS software, version 16.0 (IBM Corporation, New York, NY, USA), and a P-value $<0.05$ was considered to indicate a statistically significant result.

\section{Results}

Inverse association among IR expression in tumor tissue, preoperative serum C-peptide level, and survival in patients with RCC who underwent nephrectomy. The IR expression level in RCC tumor tissue was 0-2 (Allred score) in 10 (10.1\%), $3-5$ in $65(65.7 \%), 6$ in $15(15.2 \%)$ and $7-8$ in $9(9.1 \%)$ patients. The IGF1R expression level was $0-2$ in 12 (12.1\%), 3-5 in 59 (59.6\%), 6 in $18(18.2 \%)$ and 7-8 in 10 (10.1\%; Table I; Fig. 1) patients. The IR expression level was significantly lower in tumors of pT2 than that of pT1 and significantly lower in patients with distant metastasis than in those without $(\mathrm{P}=0.028$ and $\mathrm{P}=0.005$, respectively, Fisher's exact test, Table II). Similarly, the IR expression level was significantly lower when the preoperative serum C-peptide level was $\geq 5.14 \mathrm{ng} / \mathrm{ml}$ (median) $(\mathrm{P}=0.044$; Fisher's exact test; Table II). The preoperative serum C-peptide level was not associated with the diagnosis of type $2 \mathrm{DM}(\mathrm{P}=0.288$; Fisher's exact test).

The median follow-up duration of the patients after partial or total nephrectomy was 27 months (range, 1-71). The disease-free and overall survival were significantly better in patients with high-IR expression tumors (Allred scores of 6-8) than in those with low-IR expression tumors (Allred scores of 0-5; Table III; $\mathrm{P}=0.015$ and $\mathrm{P}=0.031$, respectively, log-rank test; Fig. 2A and B). The low IR expression level (Allred scores of 0-5); low BMI (<23.0); high T, N and M stages; and Fuhrman grades 3-4 were associated with poor disease-free and overall survival in the univariate analysis. High-IR expression level (Allred scores of 6-8) was not an independent predictor of better disease-free and overall survival in the multivariate analysis (Cox proportional hazard model; Table III). The preoperative serum C-peptide level was not associated with disease-free or overall survival (Table III). Moreover, overall survival was significantly better in patients with a body mass index (BMI) $\geq 23.0$ than in patients with a $\mathrm{BMI}<23.0(\mathrm{P}=0.041, \log$-rank test; Fig. $2 \mathrm{E}$ and $\mathrm{F})$. In contrast, the IGF1R expression level in the RCC specimens, preoperative serum IGF1 level, and clinical parameters were not associated with overall or disease-free survival, although, the statistical power of the 99 patients was insufficient to detect differences (Fig. 2C and D; Table III).

Enhanced in vitro RENCA proliferation with insulin treatment. With the use of immunoblotting, IR was shown to be expressed in Caki-2 (human RCC), RENCA (murine RCC) and $\mathrm{LNCaP}$ (human prostate cancer) cell lines, whereas IR expression was absent in 786-O (human RCC), ACHN (human RCC) and Caki-1 (human RCC) cell lines. IGF1R was expressed in 786-O, ACHN, Caki-1, Caki-2, RENCA and LNCaP cell lines (Fig. 3A). RENCA cell proliferation was stimulated by insulin in a dose-dependent manner (Fig. 3B). To analyze the in vitro effect of insulin and IR on RENCA cell proliferation, immunoblotting was performed using a protein lysate of RENCA that was stimulated by various concentrations of insulin for $30 \mathrm{~min}$. Phosphorylation of IR and Akt located downstream of IR was stimulated by insulin in a dosedependent manner $(\mathrm{P}<0.001$; Fig. 3C). The total IR protein level was not altered in vitro according to the insulin concentration of the medium (Fig. 3C). Phosphorylation of p44/42MAPK in RENCA was not enhanced by insulin in vitro. The results suggested that insulin-dependent proliferation of RENCA cells was induced by stimulation of the PI3K/Akt/mTOR pathway rather than by stimulation of the MAPK pathway in vitro.

No enhancement of in vivo progression of RENCA tumors in hyperinsulinemic obese mice induced by a high-carbohydrate 
Table II. Relationship between status of IR and IGF1R expression, and clinical parameters.

\begin{tabular}{|c|c|c|c|c|c|c|}
\hline \multirow[b]{2}{*}{ Parameters } & \multicolumn{3}{|c|}{ IR expression score ${ }^{a}$} & \multicolumn{3}{|c|}{ IGF1R expression score ${ }^{\mathrm{a}}$} \\
\hline & $\begin{array}{c}6-8(\mathrm{n}=24) \\
\mathrm{n}(\%)\end{array}$ & $\begin{array}{c}0-5(\mathrm{n}=75) \\
\mathrm{n}(\%)\end{array}$ & P-value & $\begin{array}{c}6-8(\mathrm{n}=28) \\
\mathrm{n}(\%)\end{array}$ & $\begin{array}{c}0-5(\mathrm{n}=71) \\
\mathrm{n}(\%)\end{array}$ & P-value \\
\hline Gender & & & & & & 0.921 \\
\hline Male & $14(20.0)$ & $56(80.0)$ & 0.125 & $20(29.0)$ & $50(71.0)$ & \\
\hline Female & $10(34.5)$ & $19(65.5)$ & & $8(27.6)$ & $21(72.4)$ & \\
\hline Age (years) & & & & & & 0.949 \\
\hline$\geq$ Median (65) & $12(24.0)$ & $38(76.0)$ & 0.954 & $14(28.0)$ & $36(72.0)$ & \\
\hline$<\operatorname{Median}(65)$ & $12(24.5)$ & $37(75.5)$ & & $14(29.0)$ & $35(71.0)$ & \\
\hline BMI & & & & & & 0.068 \\
\hline$\geq \operatorname{Median}(23.0)$ & $16(32.0)$ & $34(68.0)$ & 0.055 & $16(32.0)$ & $34(68.0)$ & \\
\hline$<$ Median (23.0) & $8(16.3)$ & $41(83.7)$ & & $8(16.4)$ & $41(83.6)$ & \\
\hline Serum C-peptide (ng/ml) & & & & & & 0.610 \\
\hline$\geq \operatorname{Median}(5.14)$ & $8(16.0)$ & $42(84.0)$ & 0.044 & $13(26.0)$ & $37(74.0)$ & \\
\hline$<$ Median (5.14) & $16(32.6)$ & $33(67.4)$ & & $15(30.7)$ & $34(69.3)$ & \\
\hline Serum IGF1 (ng/ml) & & & & & & 0.701 \\
\hline$\geq \operatorname{Median}(116)$ & $11(22.0)$ & $39(78.0)$ & 0.598 & $15(30.0)$ & $35(70.0)$ & \\
\hline$<\operatorname{Median}(116)$ & $13(26.6)$ & $36(73.4)$ & & $13(26.6)$ & $36(73.4)$ & \\
\hline Type 2 diabetes mellitus & & & & & & 0.318 \\
\hline Yes & $3(15.7)$ & $16(84.3)$ & 0.261 & $4(21.1)$ & $15(78.9)$ & \\
\hline No & $21(26.3)$ & $59(73.7)$ & & $24(30.0)$ & $56(70.0)$ & \\
\hline Fuhrman grade & & & & & & 0.447 \\
\hline $3-4$ & $5(14.7)$ & $29(85.3)$ & 0.085 & $8(17.6)$ & $26(82.4)$ & \\
\hline $1-2$ & $19(29.2)$ & $46(70.8)$ & & $20(30.7)$ & $45(69.3)$ & \\
\hline T stage & & & & & & 0.089 \\
\hline$\geq \mathrm{pT} 2$ & $4(11.8)$ & $30(88.2)$ & 0.028 & $6(11.8)$ & $28(88.2)$ & \\
\hline$\leq \mathrm{pT} 1$ & $20(30.8)$ & $45(69.2)$ & & $22(33.9)$ & $43(66.1)$ & \\
\hline $\mathrm{N}$ stage & & & & & & 0.051 \\
\hline N1-2 & $1(9.1)$ & $10(90.9)$ & 0.196 & $6(54.5)$ & $5(45.4)$ & \\
\hline No & $23(26.1)$ & $65(73.9)$ & & $22(25.0)$ & $66(75.0)$ & \\
\hline M stage & & & & & & 0.439 \\
\hline M1 & $0(0.0)$ & $17(100.0)$ & 0.005 & $4(23.5)$ & $13(76.5)$ & \\
\hline M0 & $24(29.2)$ & $58(70.8)$ & & $24(29.2)$ & $58(70.8)$ & \\
\hline Histological type & & & & & & 0.880 \\
\hline Clear cell carcinoma & $20(24.0)$ & $63(76.0)$ & 0.665 & $24(27.7)$ & $60(72.3)$ & \\
\hline Others & $4(25.0)$ & $12(75.0)$ & & $4(31.3)$ & $11(68.7)$ & \\
\hline
\end{tabular}

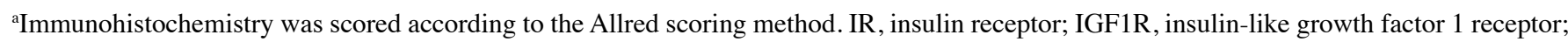
BMI, body mass index.

diet. To investigate the in vivo contribution of obesity, serum insulin and IR on murine RENCA progression, $24 \mathrm{C} 57 \mathrm{BL} / 6 \mathrm{NCrl}$ mice were divided into high-carbohydrate and low-carbohydrate groups. During the first 50 days of the experimental diets, the mouse body weights were significantly higher in the high-carbohydrate group than in the low-carbohydrate group $(\mathrm{P}=0.001$, repeated measures ANOVA; Fig. 4A). At day 56 on the diets, the mean serum glucose level was significantly higher in the high-carbohydrate group than that in the low-carbohydrate group at 30, 60 and $90 \mathrm{~min}$ after the $1.5 \mathrm{~g} / \mathrm{kg}$ glucose injections $(\mathrm{P}=0.014$, repeated measures ANOVA; Fig. 4B). At day 62 on the diets, a total of $2 \times 10^{5}$ RENCA cells were subcutaneously injected into the right flanks of the C57BL/6 NCrl mice in the 2 groups. Thirty days after the injections, the mice were euthanized under anesthesia using isoflurane to collect blood and excise the tumors. The mean fasting serum insulin level was significantly higher in the high-carbohydrate group than this level in the low-carbohydrate group ( $\mathrm{P}=0.029$, Student's t-test; Fig. 4C). However, the mean tumor volume was not 

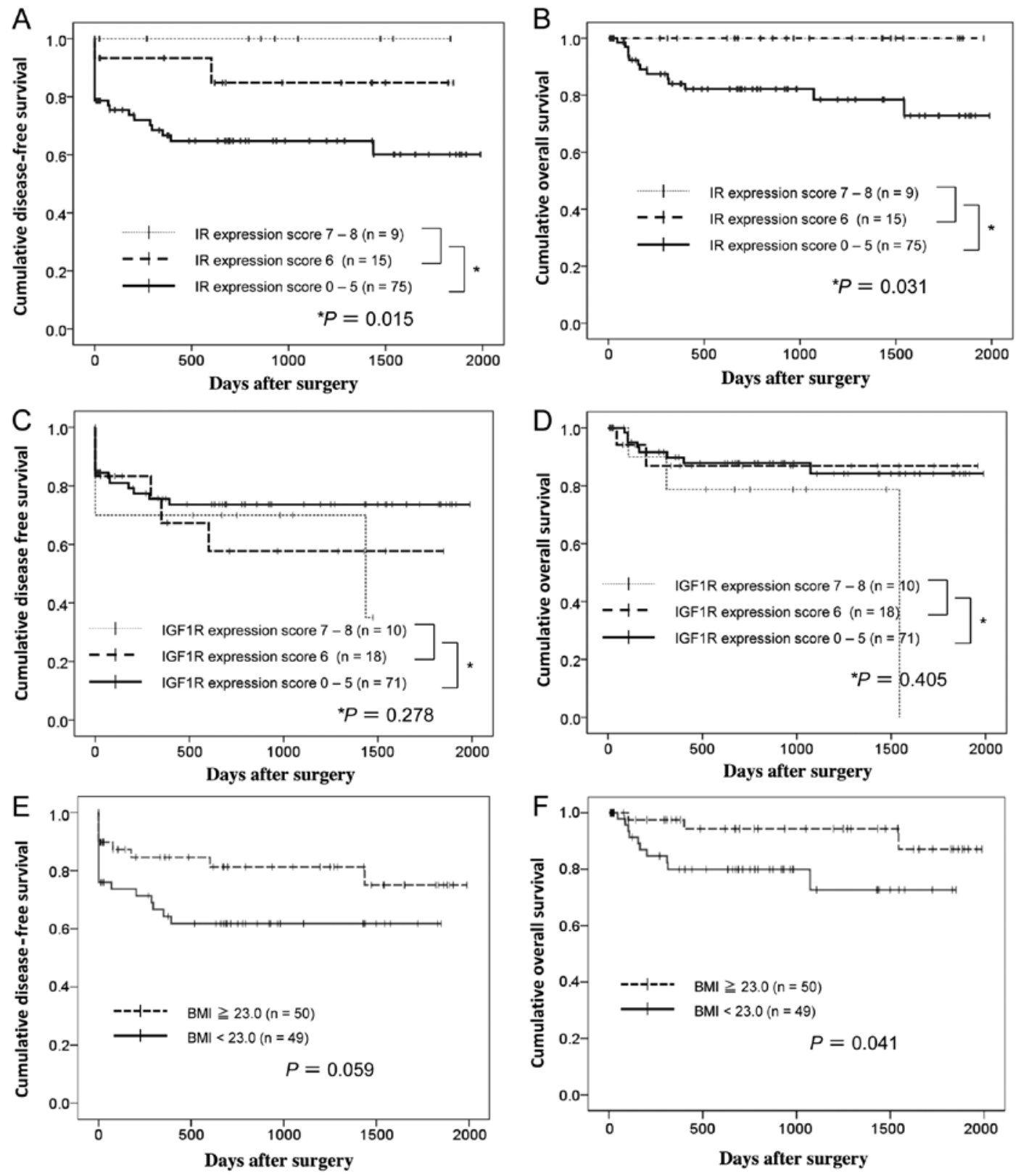

Figure 2. Disease-free and overall survival after nephrectomy according to the IR and IGF1R expression scores and BMI. (A) Disease-free survival was significantly better in patients with high-IR expression tumors (Allred score 6-8) than in patients with low-IR expression tumors (Allred score $0-5)(\mathrm{P}=0.015, \log -\mathrm{rank}$ test). (B) Overall survival was significantly better in patients with high-IR expression (Allred score 6-8) tumors than in patients with low-IR expression (Allred score 0-5) tumors ( $\mathrm{P}=0.031$, log-rank test). (C) There was no significant difference in disease-free survival between patients with high-IGF1R expression (Allred scores of 6-8) tumors and those with low-IGF1R expression (Allred scores of 0-5) tumors ( $\mathrm{P}=0.308, \log$-rank test). (D) There was no significant difference in overall survival between patients with high-IGF1R expression (Allred scores of 6-8) tumors and those with low-IGF1R expression (Allred scores of 0-5) tumors ( $\mathrm{P}=0.409$, log-rank test). (E) There was no significant difference in disease-free survival between the groups with a BMI $\geq 23.0$ and a BMI $<23.0$ ( $\mathrm{P}=0.059$, log-rank test). (F) Overall survival was significantly better in patients with a $\mathrm{BMI} \geq 23.0$ than in patients with a $\mathrm{BMI}<23.0(\mathrm{P}=0.041, \log -\mathrm{rank}$ test). IR, insulin receptor; IGF1R, insulin-like growth factor 1 receptor;. BMI, body mass index.

significantly higher in the high-carbohydrate group than that in the low-carbohydrate group $(\mathrm{P}=0.127$, repeated measures ANOVA; Fig. 4D).

Decreased IR expression in RENCA tumors in hyperinsulinemic mice. To investigate the effect of hyperinsulinemia on insulin signaling, tumor tissues were analyzed by immunoblotting. Although, phosphorylated IR was not detected in the tumors, total IR expression was significantly lower in the tumors in the high-carbohydrate group than that in the low-carbohydrate group, as determined by densitometry $(\mathrm{n}=5$,
$\mathrm{P}=0.008$; Fig. 4E and F). In contrast, phosphorylation of both Akt and p44 MAPK was significantly enhanced in the tumors in the high-carbohydrate group $(\mathrm{P}=0.010$ and $\mathrm{P}=0.090$, respectively). In in vitro experiments, the proliferation of RENCA cells was presumably enhanced by phosphorylation of Akt rather than by the p44 MAPK pathway (Fig. 3C). However, in vivo, RENCA tumor progression was presumably enhanced via both phosphorylation of Akt and p44 MAPK in the mice with hyperinsulinemia. Although the mean tumor volume was not significantly higher in the high-carbohydrate group than that in the low-carbohydrate group statistically, an alternative 


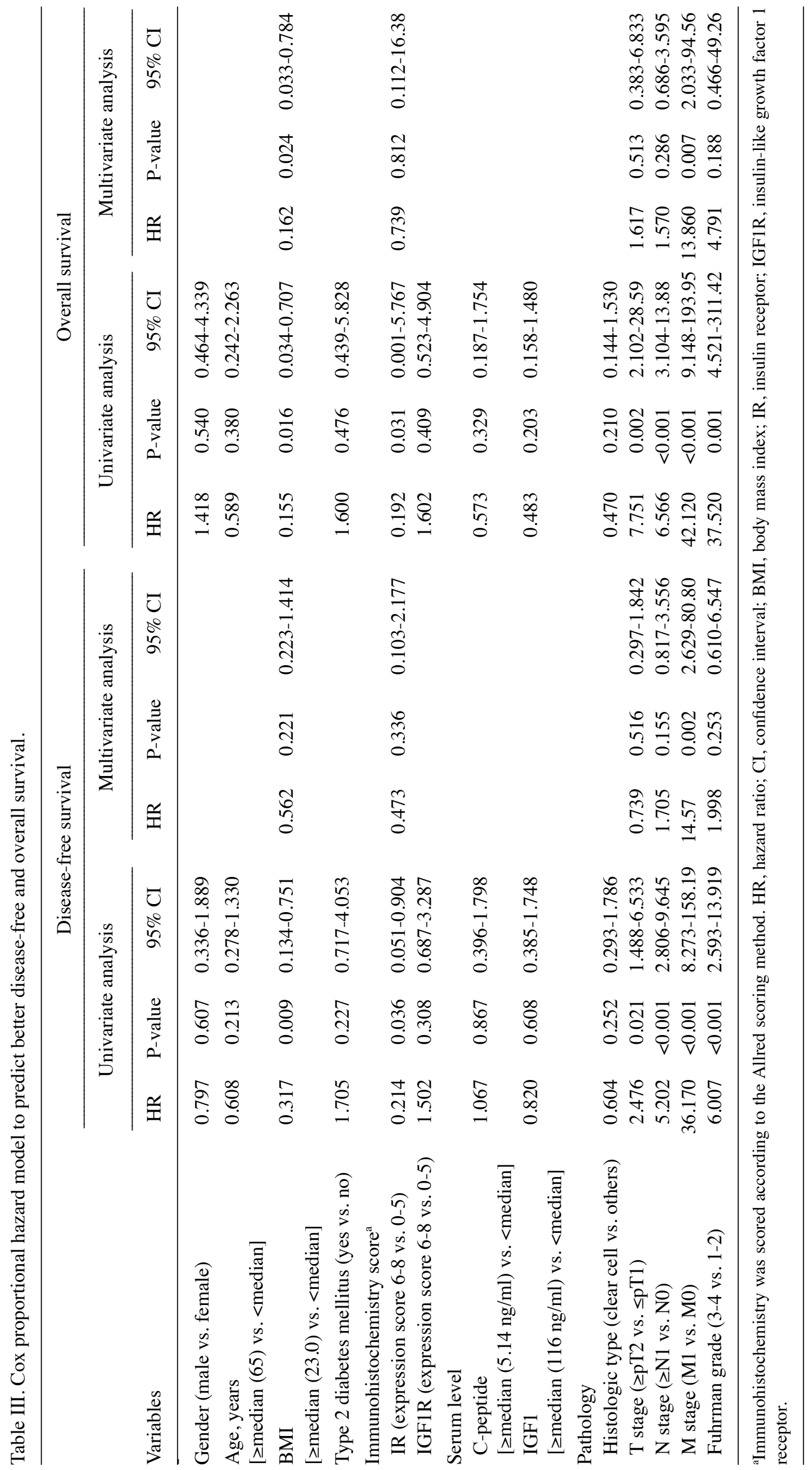




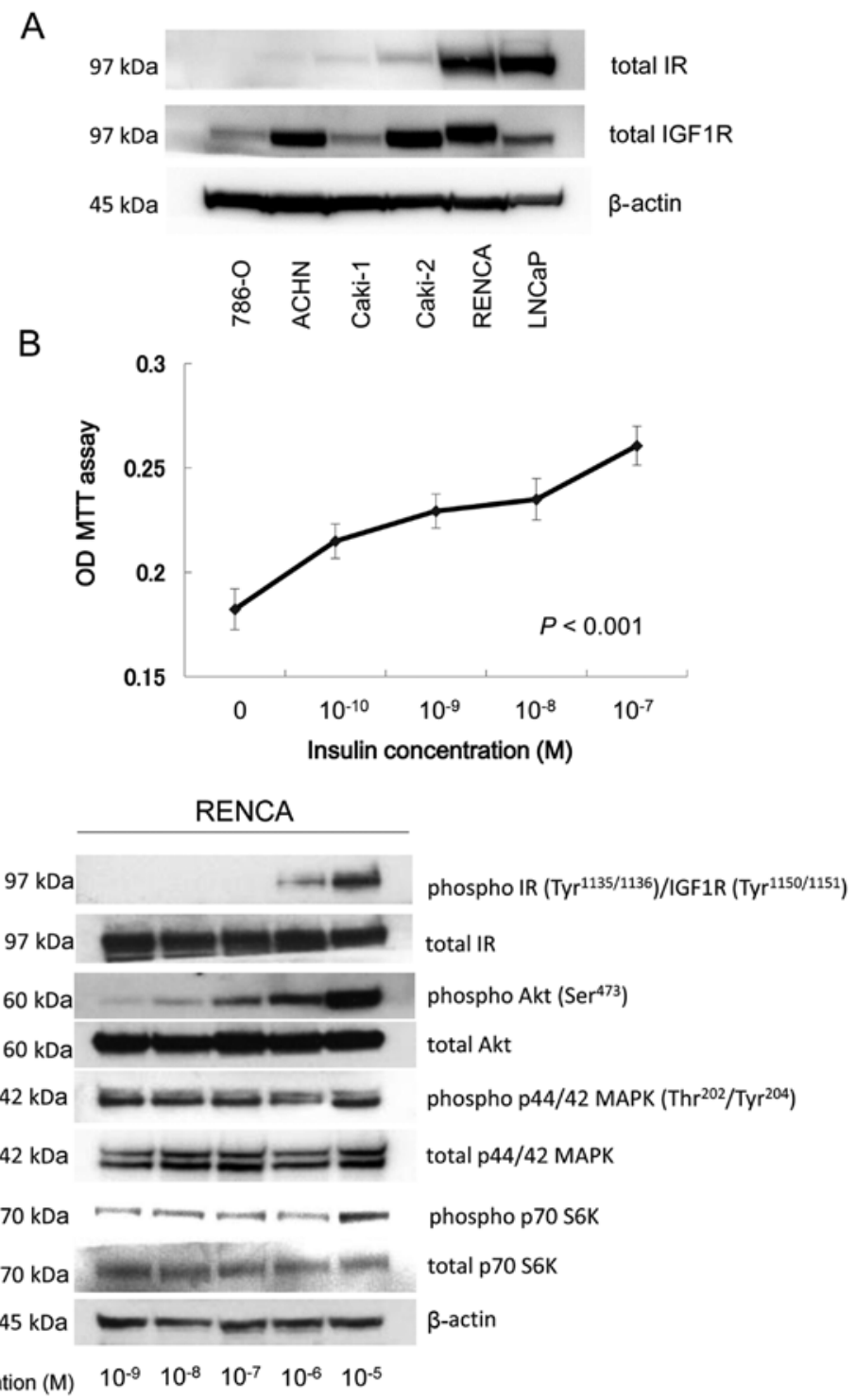

Figure 3. IR and IGF1R expression in various RCC cell lines and enhanced in vitro RENCA proliferation with insulin treatment. (A) Proteins (30 $\mu \mathrm{g}$ ) extracted from various human and mouse cell lines were size fractionated using SDS-PAGE and immunoblotted using total IR- $\beta$ subunit and IGF1R antibodies. (B) RENCA cells were plated at $5 \times 10^{3}$ cells/well onto 96-well plates in culture medium containing 10\% FBS. After a 24-h incubation in serum-free medium, the complete medium was replaced with a test medium containing various doses of insulin for $72 \mathrm{~h}$. After incubation with $1 \mathrm{mg} / \mathrm{ml} \mathrm{MTT} \mathrm{solution} \mathrm{for}$ $3 \mathrm{~h}, 0.05 \mathrm{~N}$ isopropanol-HCl solution was added and the OD was assessed. (C) RENCA cells were plated on 10-cm Petri dishes in culture medium containing $10 \%$ FBS. After a 24-h incubation in serum-free medium, the complete medium was replaced with test medium containing various doses of insulin for 30 min. Then, the proteins $(30 \mu \mathrm{g})$ extracted from the cells were size fractionated using SDS-PAGE and immunoblotted with phospho- and total IR, Akt, p44/42 MAPK and p70S6K antibodies. IR, insulin receptor; IGF1R, insulin-like growth factor 1 receptor; RCC, renal cell carcinoma; OD, optical density.

signaling pathway, distinct from that in the in vitro experiment, may have been involved in the in vivo progression of RENCA tumors induced by the hyperinsulinemic and obesity-inducing environment under a high-carbohydrate diet.

Direct anticancer effect of metformin in murine RENCA tumors rather than the indirect effect of lowering the serum insulin level. To investigate the in vivo contribution of hyperinsulinemia on RENCA tumor progression, $48 \mathrm{C} 57 \mathrm{BL} / 6 \mathrm{NCrl}$ mice were divided into 4 groups: the high-carbohydrate diet, high-carbohydrate diet + metformin, low-carbohydrate diet and low-carbohydrate diet + metformin groups. Among the possible mechanisms underlying the cancer-suppressing effect of metformin, direct regulation of cancer signaling via stimulation of AMP-activated protein kinase (AMPK) and an indirect effect of lowering the serum insulin level via hepatocytes have been proposed $(3,40)$.

During the first 98 days after initiation of the experimental diets, the mouse body weights were significantly higher in the high-carbohydrate diet group than those in the low-carbohydrate diet group, and were significantly lower in the high-carbohydrate diet + metformin group than those in the high-carbohydrate diet group $(\mathrm{P}=0.001$ and $\mathrm{P}=0.026$, repeated measures ANOVA; Fig. 5A). In addition, as determined by the glucose tolerance test at 98 days after diet initiation, glucose levels were significantly higher in the high-carbohydrate diet group than those in the low-carbohydrate diet group, and were relatively lower in the high-carbohydrate + metformin group than those in the high-carbohydrate diet group $(\mathrm{P}=0.001$ and $\mathrm{P}=0.090$, repeated measures ANOVA; Fig. 5B). 

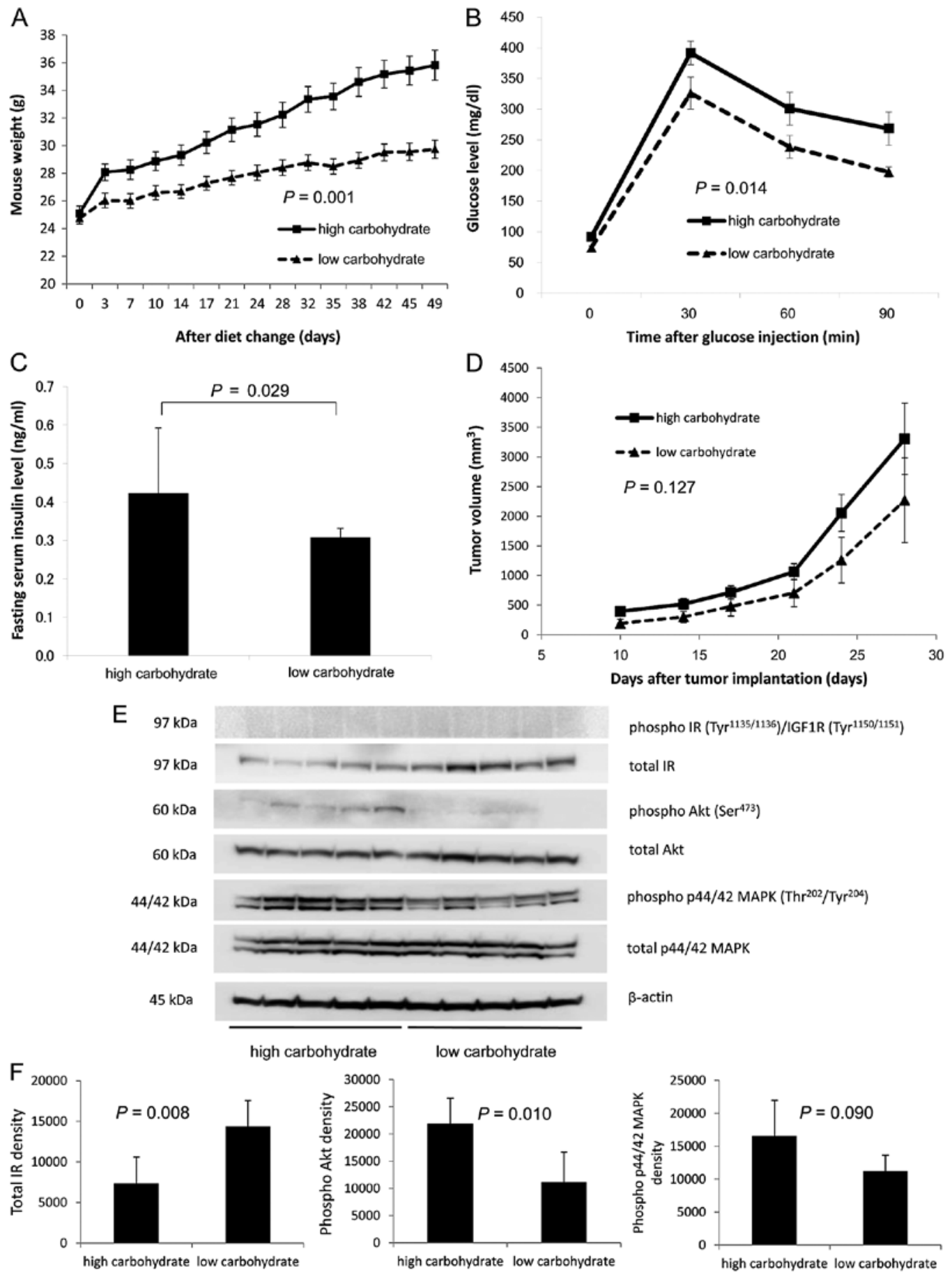

Figure 4. In vivo progression of RENCA tumors in hyperinsulinemic obese mice induced by a high-carbohydrate diet. Comparison of (A) body weight, (B) serum glucose levels determined by a glucose tolerance test, (C) fasting serum insulin levels, (D) flank subcutaneous tumor volumes, (E) tumor insulin signaling assessed by immunoblottings, and (F) densitometry of each protein in the tumors between the mouse high-carbohydrate diet and low-carbohydrate diet groups. (A) Body weights of $\mathrm{C} 57 \mathrm{BL} / 6 \mathrm{NCrl}$ mice in each group were assessed twice/week. (B) Glucose tolerance tests were performed at 56 days after the randomization. Blood glucose levels were assessed before i.p. injection of $1.5 \mathrm{~g} / \mathrm{kg}$ glucose at 30,60 and $90 \mathrm{~min}$ after the glucose injection using a OneTouch Ultra glucometer and blood collected from a cut saphenous vein. (C) At 92 days after the randomization, all mice were fasted overnight and euthanized under anesthesia to collect blood and excise the tumors. Blood samples were collected from the left ventricle using 24-gauge needles. The collected blood was centrifuged, and the serum was stored at $-80^{\circ} \mathrm{C}$. The serum insulin levels were assessed using a rat/mouse ELISA kit. (D) A total of $2 \times 10^{5}$ RENCA cells were injected subcutaneously into the right flanks of the mice 62 days after the randomization. Once a tumor became palpable, the tumor volume was calculated twice a week according to the formula: [Tumor volume $=(\text { short diameter })^{2} \mathrm{x}$ long diameter $\mathrm{x} 0.52$ ]. (E) Tumor tissues were homogenized in the lysis buffer containing a protease inhibitor and phosphatase inhibitor cocktail. The lysates were centrifuged, and the supernatant was stored at $-80^{\circ} \mathrm{C}$. A total of $30 \mu \mathrm{g}$ of protein lysate was size fractionated using SDS-PAGE and immunoblotted using phospho- and total IR, Akt and p44/42 MAPK antibodies. (F) The signal was captured using a chemiluminescence imaging system. IR, insulin receptor.

At 133 days after diet initiation, a total of $2 \times 10^{5}$ RENCA cells were subcutaneously injected into the mice in each of the 4 groups. Thirty days after the injection, the mice were euthanized to collect blood and excise the tumors. The mean fasting serum insulin level was significantly higher in the high-carbohydrate diet group than that in the low-carbohydrate 

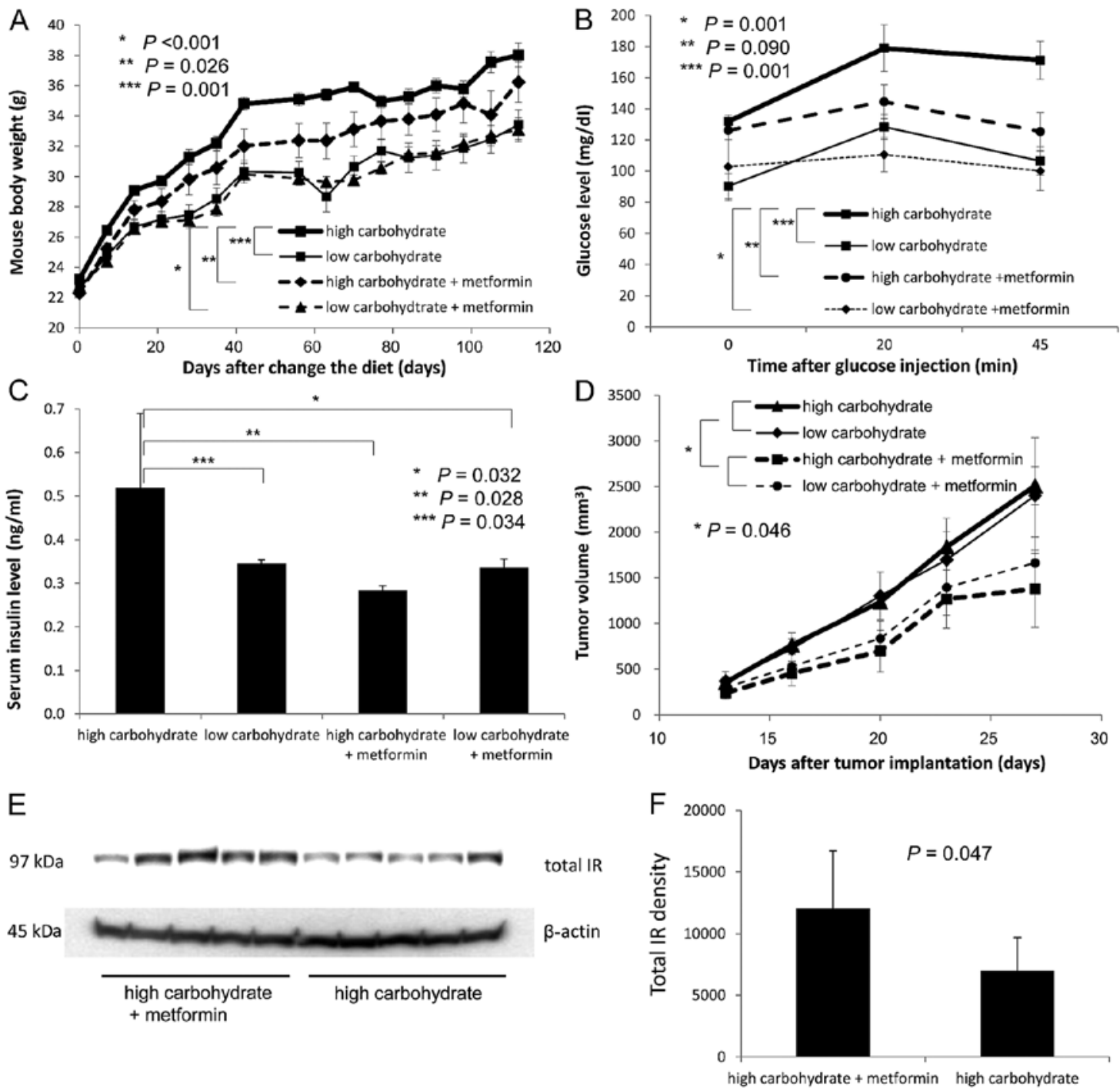

Figure 5. In vivo effects of metformin in RENCA tumors in hyperinsulinemic obese mice induced by a high-carbohydrate diet. Comparison of (A) body weight, (B) serum glucose levels determined by a glucose tolerance test, (C) fasting serum insulin levels, (D) flank subcutaneous tumor volumes, (E) tumor-insulin signaling assessed by immunoblottings, and (F) densitometry of each protein in the tumors among the mouse high- and low-carbohydrate diet, high-carbohydrate diet + metformin, and low-carbohydrate diet + metformin groups. (A) Body weight of C57BL/6 NCrl mice in each group was assessed twice/week. (B) Glucose tolerance tests were performed at 98 days after the randomization. (C) At 163 days after the randomization, all mice were fasted overnight and euthanized under anesthesia to collect blood and excise the tumors. The serum insulin level was assessed using a rat/mouse ELISA kit. (D) A total of $2 \times 10^{5}$ RENCA cells were injected subcutaneously into the right flanks of the mice at 133 days after the randomization. (E) A total of $30 \mu \mathrm{g}$ of protein lysate was size fractionated using SDS-PAGE and immunoblotted using total IR antibody. (F) The IR expression was captured using a chemiluminescence imaging system. IR, insulin receptor.

diet group, and significantly lower in the high-carbohydrate diet + metformin group than that in the high-carbohydrate group at euthanasia $(\mathrm{P}=0.034$ and $\mathrm{P}=0.028$; Fig. $5 \mathrm{C})$. Although, the mean tumor volume was not significantly higher in the high-carbohydrate group than that in the low-carbohydrate diet group, the mean tumor volumes were significantly lower in both the high- and low-carbohydrate diet + metformin groups than the tumor volumes in the high- and low-carbohydrate diet without metformin groups ( $\mathrm{P}=0.046$; Fig. 5D).

Enhanced IR expression in RENCA tumors with metformin treatment. Although, phosphorylated IR was not detected in the tumor tissues by immunoblotting analysis, total IR expression was significantly higher in the tumors of the high-carbohydrate diet + metformin group than that in the high-carbohydrate diet group determined by densitometry ( $\mathrm{P}=0.047$; Fig. $5 \mathrm{E}$ and $\mathrm{F})$.
Acceleration of RENCA tumor progression by a high-carbohydrate diet was not observed in this experiment, and tumor progression was inhibited by metformin not only in the hyperinsulinemic mice, but also in the normoinsulinemic mice. The results suggested that the mechanism of the metformin effect in this model was the direct effect of enhancement of AMPK rather than the indirect effect of lowering the serum insulin level. Of interest, IR expression was increased in the tumors of the hyperinsulinemic mice treated with metformin (Fig. 5E and F).

Metformin directly inhibits in vitro RENCA proliferation. To confirm the direct effect of metformin on the inhibition of the proliferation of RENCA cells in vitro, a cell proliferation assay under various concentrations of metformin with $4 \mu \mathrm{g} / \mathrm{ml}$ of insulin was evaluated. In vitro stimulation of RENCA cells 


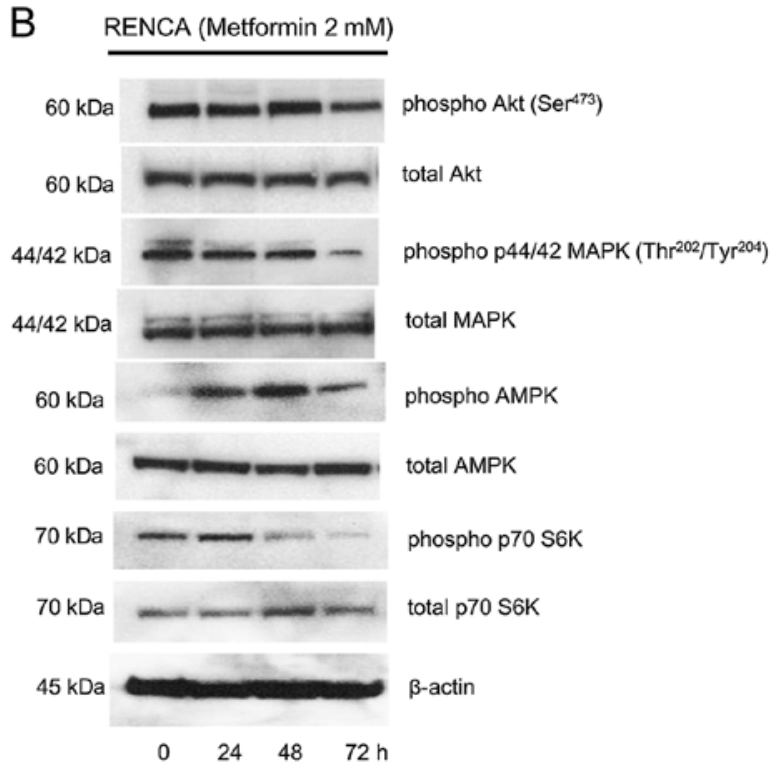

Figure 6. In vitro direct effect of metformin on the proliferation of RENCA cells. (A) RENCA cells were plated at 5x10 $0^{3}$ cells/well onto 96-well plates in culture medium containing $10 \%$ FBS. The complete medium was replaced with test medium containing various doses of metformin and various doses of metformin plus $5 \mu \mathrm{g} / \mathrm{ml}$ of insulin for $24 \mathrm{~h}$. After incubation with $1 \mathrm{mg} / \mathrm{ml}$ MTT solution for $3 \mathrm{~h}, 0.05 \mathrm{~N}$ isopropanol-HCl solution was added and the OD was assessed. (B) RENCA cells were plated onto $10-\mathrm{cm}$ Petri dishes in culture medium containing $10 \%$ FBS. The complete medium was replaced with test medium with and without $2 \mathrm{mM}$ metformin for 0,24, 48 and $72 \mathrm{~h}$. Subsequently, proteins $(30 \mu \mathrm{g})$ extracted from the cells were size fractionated using SDS-PAGE and immunoblotted using phospho- and total Akt, p44/42 MAPK, AMPK and p70 S6K antibodies. OD, optical density.

by insulin was inhibited in a dose-dependent manner by metformin at $24 \mathrm{~h}$ (Fig. 6A). Since, the suppressive effect of metformin on RENCA cells was observed both in the presence and absence of insulin supplementation in vitro, metformin directly inhibited in vitro RENCA proliferation (Fig. 6A). The results of immunoblotting showed that metformin enhanced the phosphorylation of AMPK at 24-48 $\mathrm{h}$ and inhibited that of Akt, p44 MAPK and p70 S6K at 48-72 h (Fig. 6B).

\section{Discussion}

In the immunohistochemistry evaluation of RCC tumor specimens, IR expression significantly decreased in tumors of $\geq \mathrm{pT} 2$, patients with distant metastasis, and patients with serum C-peptide levels higher than the median (Table II). Disease-free and overall survival were significantly better in patients with high-IR expression tumors (Allred scores of 6-8) than in those with low-IR expression tumor (Allred scores of 0-5; Fig. 2A and B; Table III). These results suggested that a patient's hyperinsulinemia decreases the IR expression in RCC tumors of aggressive phenotypes. However, preoperative serum C-peptide level was not associated with disease-free or overall survival in the present study. Furthermore, IR expression in RCC tumor tissue was higher in low-grade tumors than in high-grade tumors, although, the difference was not statistically significant $(\mathrm{P}=0.085)$. The IR expression in human $\mathrm{RCC}$ cell lines was observed in Caki-2 cells that were derived from primary tumors, whereas it was absent in ACHN and Caki-1 cells that were derived from metastatic disease (Fig. 3A). A recent study from a Korean group showed similar results, although the researchers did not observe a significant relationship between survival and IR expression (30). A similar inverse relationship among IR expression, tumor grade and patient survival has been previously reported in breast cancer $(32,33)$.
The decreased IR expression in the murine RCC allograft model in obese, hyperglycemic and hyperinsulinemic mice induced by a high-carbohydrate diet was consistent with the results from the immunohistochemical analysis of clinical RCC surgical specimens. Moreover, decreased serum insulin levels, which were induced by metformin treatment, increased IR expression in the high-carbohydrate diet group (Fig. 5E and F). These results suggest the presence of a negative feedback pathway associated with the serum insulin level that regulated the IR expression level in RCC tumor cells. In support of this theory, a previous study showed that IR expression decreased in intact skeletal muscle strips from obese and hyperinsulinemic patients (41). In contrast, a previous prostate cancer LNCaP xenograft study showed a positive relationship between hyperinsulinemia and IR expression (38). The IR expression level in normal or malignant cells may be positively or inversely regulated distinctively by the serum insulin level according to the origin of the tissue cell.

In the present murine RCC allograft model, a weak tumor-promoting effect in RENCA tumors was associated with a high-carbohydrate diet (Fig. 4D). Cell proliferation and phosphorylation of Akt in RENCA cells were enhanced by insulin in an in vitro study (Fig. 3C), and phosphorylation induced by a high-carbohydrate diet of Akt in RENCA cells was also observed in an in vivo study (Fig. 4E and F). In contrast, phosphorylation of MAPK was also observed in tumors in vivo but not in the in vitro cells (Fig. $4 \mathrm{E}$ and $\mathrm{F}$ ). These results suggest that pathways other than the insulin-Akt signaling pathway contributed to the weak tumor-promoting effect in the in vivo model mice induced by a high-carbohydrate diet. The results further suggest that, although, hyperinsulinemia promoted RCC cell proliferation in the in vitro study, the downregulation feedback effect of IR expression induced by hyperinsulinemia and the contribution of other growth-promoting pathways in the in vivo study may 
have complicated the effect of a high-carbohydrate diet on RCC proliferation in the in vivo RENCA allograft model.

To elucidate the real in vivo progression effect of hyperinsulinemia induced by a high-carbohydrate diet, we performed a second murine experiment using metformin to suppress hyperinsulinemia in the high-carbohydrate diet group. Metformin is a common anti-type 2 diabetes agent that lowers serum insulin levels. The key mechanism of metformin is believed to be AMPK, which inhibits mTOR. In RCC, metformin has been shown to suppress RCC progression in both in vitro and in vivo studies using the human RCC cell line 786-O (42). The mechanisms underlying the suppressive effect of metformin for various cancers have been suggested to involve direct and indirect pathways (3). The direct pathway of metformin involves stimulation of AMPK in cancer cells, which leads to decreased activity of downstream mitogenic molecules, such as Akt, mTOR and S6K. The indirect metformin pathway involves suppression of gluconeogenesis by stimulating AMPK in hepatocytes, which leads to decreased hepatic glucose output and serum glucose levels, with a secondary decrease in serum insulin levels $(3,40)$. In the present study, metformin significantly ameliorated obesity, hyperglycemia and hyperinsulinemia induced by a high-carbohydrate diet in the second in vivo experiment (Fig. 5B and C). However, the tumor suppressive effect of metformin was observed in both the low- and high-carbohydrate diet groups, even though decreased serum insulin levels were observed only in the high-carbohydrate diet group (Fig. 5D). Moreover, the direct metformin anticancer effect induced by AMPK stimulation was also observed in RENCA cells in vitro (Fig. 6). These results indicated that the tumor suppressive effect of metformin in the present study resulted from the direct effect of the agent rather than the indirect effect of suppression of serum insulin levels. The expected indirect effect of metformin, which was previously reported in a murine colorectal cancer allograft model, was not observed in the present RCC allograft model (39). Although, it may be inappropriate to apply the results of the murine allograft experiment directly to human clinical settings, the results of the present RENCA model appear to support the present clinical result that the preoperative serum C-peptide level was not associated with RCC recurrence or survival.

The clinical analysis results of the present study showed that disease-free or overall survival was significantly better in patients with a BMI greater than or equal to the median. This finding was consistent with the 'obese paradox' in RCC that has been suggested by multiple epidemiological studies (14-21) (Fig. 2E and F). The weakness or lack of a tumor acceleration effect of hyperinsulinemia observed in the present clinical and murine RCC model studies partly explained the 'obese paradox' in RCC. In contrast, the finding of a low IR expression level associated with the aggressive phenotypes of RCC, such as tumors of $\geq \mathrm{pT} 2$, or poor disease-free survival in the present clinical analysis was contradictory (Tables II and III). The discrepancy could be explained by the hypothesis that hyperinsulinemia may have a stronger role in carcinogenesis of aggressive types of RCC rather than in cancer progression after tumor development. Notably, Othman et al reported insulin-mediated genotoxicity associated with the PI3K-Akt signaling pathway in kidney cells (43), and this type of genotoxicity causes the genesis of aggressive types of RCC with DNA hypermutations. Further investigation is warranted to elucidate the mechanism of the 'obesity paradox' in RCC progression.

Collectively, we found that IR expression in RCC tissue was inversely associated with cancer progression in the clinical and murine experimental model studies. The anticancer effect of metformin in the murine RCC experimental model was mainly a direct effect of metformin rather than an indirect effect involving suppression of serum insulin levels. The tumor-promoting effect of hyperinsulinemia in RENCA tumors was not clearly observed in either the clinical or murine experimental model studies. Decreased IR expression in high-stage RCC tumors with poor prognosis may be the result of downregulation induced by the host's hyperinsulinemia.

\section{Acknowledgements}

The present study was in part supported by grants (nos. 23791738, 24592373, 24592374, 25462466, 25293332 and 26670695) from the Japanese Society for the Promotion of Science.

\section{References}

1. Cohen DH and LeRoith D: Obesity, type 2 diabetes, and cancer: The insulin and IGF connection. Endocr Relat Cancer 19: F27-F45, 2012

2. Ohnishi H, Saitoh S, Takagi S, Ohata J, Takeuchi H, Isobe T, Katoh N, Chiba Y, Fujiwara T, Akasaka H, et al: Incidence of insulin resistance in obese subjects in a rural Japanese population: The Tanno and Sobetsu study. Diabetes Obes Metab 7: 83-87, 2005.

3. Pollak M: Insulin and insulin-like growth factor signalling in neoplasia. Nat Rev Cancer 8: 915-928, 2008.

4. Nepple KG, Yang L, Grubb RL III and Strope SA: Population based analysis of the increasing incidence of kidney cancer in the United States: Evaluation of age specific trends from 1975 to 2006. J Urol 187: 32-38, 2012.

5. Bergström A, Hsieh CC, Lindblad P, Lu CM, Cook NR and Wolk A: Obesity and renal cell cancer - a quantitative review. $\mathrm{Br}$ J Cancer 85: 984-990, 2001.

6. Calle EE, Rodriguez C, Walker-Thurmond $\mathrm{K}$ and Thun MJ: Overweight, obesity, and mortality from cancer in a prospectively studied cohort of U.S. adults. N Engl J Med 348: 1625-1638, 2003.

7. Renehan AG, Tyson M, Egger M, Heller RF and Zwahlen M: Body-mass index and incidence of cancer: A systematic review and meta-analysis of prospective observational studies. Lancet 371: 569-578, 2008.

8. Sawada N, Inoue M, Sasazuki S, Iwasaki M, Yamaji T, Shimazu T and Tsugane S; JPHC Study Group: Body mass index and subsequent risk of kidney cancer: A prospective cohort study in Japan. Ann Epidemiol 20: 466-472, 2010.

9. Wideroff L, Gridley G, Mellemkjaer L, Chow WH, Linet M, Keehn S, Borch-Johnsen K and Olsen JH: Cancer incidence in a population-based cohort of patients hospitalized with diabetes mellitus in Denmark. J Natl Cancer Inst 89: 1360-1365, 1997.

10. Inoue M, Iwasaki M, Otani T, Sasazuki S, Noda M and Tsugane S: Diabetes mellitus and the risk of cancer: Results from a large-scale population-based cohort study in Japan. Arch Intern Med 166: 1871-1877, 2006.

11. Washio M, Mori M, Khan M, Sakauchi F, Watanabe Y, Ozasa K, Hayashi K, Miki T, Nakao M, Mikami K, et al; JACC Study Group: Diabetes mellitus and kidney cancer risk: The results of Japan Collaborative Cohort Study for Evaluation of Cancer Risk (JACC Study). Int J Urol 14: 393-397, 2007.

12. Pierce BL, Plymate S, Ostrander EA and Stanford JL: Diabetes mellitus and prostate cancer risk. Prostate 68: 1126-1132, 2008.

13. Kasper JS and Giovannucci E: A meta-analysis of diabetes mellitus and the risk of prostate cancer. Cancer Epidemiol Biomarkers Prev 15: 2056-2062, 2006. 
14. Parker AS, Lohse CM, Cheville JC, Thiel DD, Leibovich BC and Blute ML: Greater body mass index is associated with better pathologic features and improved outcome among patients treated surgically for clear cell renal cell carcinoma. Urology 68: 741-746, 2006

15. Awakura Y, Nakamura E, Ito N, Yamasaki T, Kamba T, Kamoto T and Ogawa O: Influence of body mass index on prognosis of Japanese patients with renal cell carcinoma. Urology 70: 50-54, 2007.

16. Schrader AJ, Rustemeier J, Rustemeier JC, Timmesfeld N, Varga Z, Hegele A, Olbert PJ and Hofmann R: Overweight is associated with improved cancer-specific survival in patients with organ-confined renal cell carcinoma. J Cancer Res Clin Oncol 135: 1693-1699, 2009.

17. Jeon HG, Jeong IG, Lee JH, Lee CJ, Kwak C, Kim HH, Lee SE and Lee E: Prognostic value of body mass index in Korean patients with renal cell carcinoma. J Urol 183: 448-454, 2010.

18. Waalkes S, Merseburger AS, Kramer MW, Herrmann TR, Wegener G, Rustemeier J, Hofmann R, Schrader M, Kuczyk MA and Schrader AJ: Obesity is associated with improved survival in patients with organ-confined clear-cell kidney cancer. Cancer Causes Control 21: 1905-1910, 2010.

19. Carnethon MR, De Chavez PJ, Biggs ML, Lewis CE, Pankow JS, Bertoni AG, Golden SH, Liu K, Mukamal KJ, CampbellJenkins B, et al: Association of weight status with mortality in adults with incident diabetes. JAMA 308: 581-590, 2012.

20. Choi Y, Park B, Jeong BC, Seo SI, Jeon SS, Choi HY, Adami HO, Lee JE and Lee HM: Body mass index and survival in patients with renal cell carcinoma: A clinical-based cohort and metaanalysis. Int J Cancer 132: 625-634, 2013.

21. Hakimi AA, Furberg H, Zabor EC, Jacobsen A, Schultz N, Ciriello G, Mikklineni N, Fiegoli B, Kim PH, Voss MH, et al: An epidemiologic and genomic investigation into the obesity paradox in renal cell carcinoma. J Natl Cancer Inst 105: 1862-1870, 2013.

22. Freedland SJ, Aronson WJ, Kane CJ, Presti JC Jr, Amling CL, Elashoff D and Terris MK: Impact of obesity on biochemical control after radical prostatectomy for clinically localized prostate cancer: A report by the Shared Equal Access Regional Cancer Hospital database study group. J Clin Oncol 22: 446-453, 2004

23. Ho T, Gerber L, Aronson WJ, Terris MK, Presti JC, Kane CJ, Amling CL and Freedland SJ: Obesity, prostate-specific antigen nadir, and biochemical recurrence after radical prostatectomy: Biology or technique? Results from the SEARCH database. Eur Urol 62: 910-916, 2012 .

24. Bhindi B, Kulkarni GS, Finelli A, Alibhai SM, Hamilton RJ, Toi A, van der Kwast TH, Evans A, Hersey K, Jewett MA, et al: Obesity is associated with risk of progression for low-risk prostate cancers managed expectantly. Eur Urol 66: 841-848, 2014.

25. Ladoire S, Dalban C, Roché H, Spielmann M, Fumoleau P, Levy C, Martin AL, Ecarnot F, Bonnetain F and Ghiringhelli F: Effect of obesity on disease-free and overall survival in node-positive breast cancer patients in a large French population: A pooled analysis of two randomised trials. Eur J Cancer 50: 506-516, 2014

26. Gennari A, Nanni O, Puntoni M, DeCensi A, Scarpi E, Conte P, Antonucci G, Amadori D and Bruzzi P: Body mass index and prognosis of metastatic breast cancer patients receiving first-line chemotherapy. Cancer Epidemiol Biomarkers Prev 22 $1862-1867,2013$.

27. Psutka SP, Stewart SB, Boorjian SA, Lohse CM, Tollefson MK, Cheville JC, Leibovich BC and Thompson RH: Diabetes mellitus is independently associated with an increased risk of mortality in patients with clear cell renal cell carcinoma. J Urol 192: $1620-1627,2014$
28. Antonelli A, Arrighi N, Corti S, Zanotelli T, Cozzoli A, Cosciani Cunico $S$ and Simeone C: Pre-existing type 2 diabetes is not an adverse prognostic factor in patients with renal cell carcinoma: A single-center retrospective study. Urol Oncol 31: 1310-1315, 2013

29. Kellerer M, von Eye Corleta H, Mühlhöfer A, Capp E, Mosthaf L, Bock S, Petrides PE and Häring HU: Insulin- and insulin-like growth-factor-I receptor tyrosine-kinase activities in human renal carcinoma. Int J Cancer 62: 501-507, 1995.

30. Lkhagvadorj S, Oh SS, Lee MR, Jung JH, Chung HC, Cha SK and Eom M: Insulin receptor expression in clear cell renal cell carcinoma and its relation to prognosis. Yonsei Med J 55: 861-870, 2014.

31. Law JH, Habibi G, Hu K, Masoudi H, Wang MY, Stratford AL, Park E, Gee JM, Finlay P, Jones HE, et al: Phosphorylated insulin-like growth factor-i/insulin receptor is present in all breast cancer subtypes and is related to poor survival. Cancer Res 68: 10238-10246, 2008.

32. Mulligan AM, O'Malley FP, Ennis M, Fantus IG and Goodwin PJ: Insulin receptor is an independent predictor of a favorable outcome in early stage breast cancer. Breast Cancer Res Treat 106: 39-47, 2007.

33. Mathieu MC, Clark GM, Allred DC, Goldfine ID and Vigneri R: Insulin receptor expression and clinical outcome in node-negative breast cancer. Proc Assoc Am Physicians 109: 565-571, 1997.

34. Goodwin PJ, Ennis M, Pritchard KI, Trudeau ME, Koo J, Madarnas Y, Hartwick W, Hoffman B and Hood N: Fasting insulin and outcome in early-stage breast cancer: Results of a prospective cohort study. J Clin Oncol 20: 42-51, 2002.

35. Muti P, Quattrin T, Grant BJ, Krogh V, Micheli A, Schünemann HJ, Ram M, Freudenheim JL, Sieri S, Trevisan M, et al: Fasting glucose is a risk factor for breast cancer: A prospective study. Cancer Epidemiol Biomarkers Prev 11: 1361-1368, 2002.

36. Cox ME, Gleave ME, Zakikhani M, Bell RH, Piura E, Vickers E, Cunningham M, Larsson O, Fazli L and Pollak M: Insulin receptor expression by human prostate cancers. Prostate 69: 33-40, 2009.

37. Ma J, Li H, Giovannucci E, Mucci L, Qiu W, Nguyen PL, Gaziano JM, Pollak M and Stampfer MJ: Prediagnostic body-mass index, plasma C-peptide concentration, and prostate cancer-specific mortality in men with prostate cancer: A long-term survival analysis. Lancet Oncol 9: 1039-1047, 2008.

38. Venkateswaran V, Haddad AQ, Fleshner NE, Fan R, Sugar LM, Nam R, Klotz LH and Pollak M: Association of diet-induced hyperinsulinemia with accelerated growth of prostate cancer (LNCaP) xenografts. J Natl Cancer Inst 99: 1793-1800, 2007.

39. Allred DC, Harvey JM, Berardo M and Clark GM: Prognostic and predictive factors in breast cancer by immunohistochemical analysis. Mod Pathol 11: 155-168, 1998.

40. Algire C, Zakikhani M, Blouin MJ, Shuai JH and Pollak M: Metformin attenuates the stimulatory effect of a high-energy diet on in vivo LLC1 carcinoma growth. Endocr Relat Cancer 15: 833-839, 2008

41. Goodyear LJ, Giorgino F, Sherman LA, Carey J, Smith RJ and Dohm GL: Insulin receptor phosphorylation, insulin receptor substrate-1 phosphorylation, and phosphatidylinositol 3-kinase activity are decreased in intact skeletal muscle strips from obese subjects. J Clin Invest 95: 2195-2204, 1995.

42. Liu J, Li M, Song B, Jia C, Zhang L, Bai X and Hu W: Metformin inhibits renal cell carcinoma in vitro and in vivo xenograft. Urol Oncol 31: 264-270, 2013.

43. Othman EM, Hintzsche H and Stopper H: Signaling steps in the induction of genomic damage by insulin in colon and kidney cells. Free Radic Biol Med 68: 247-257, 2014. 